\title{
Year-round operation the solar powered hybrid adsorption-compression refrigeration cycle
}

Piotr CYKLIS, Roman DUDA

DOI: 10.30464/jmee.2019.3.4.317

Cite this article as:

Cyklis P., Duda R. Year-round operation the solar powered hybrid adsorption-compression refrigeration cycle. Journal of Mechanical and Energy Engineering, Vol. 3(43), No. 4, 2019, pp. 317-322.

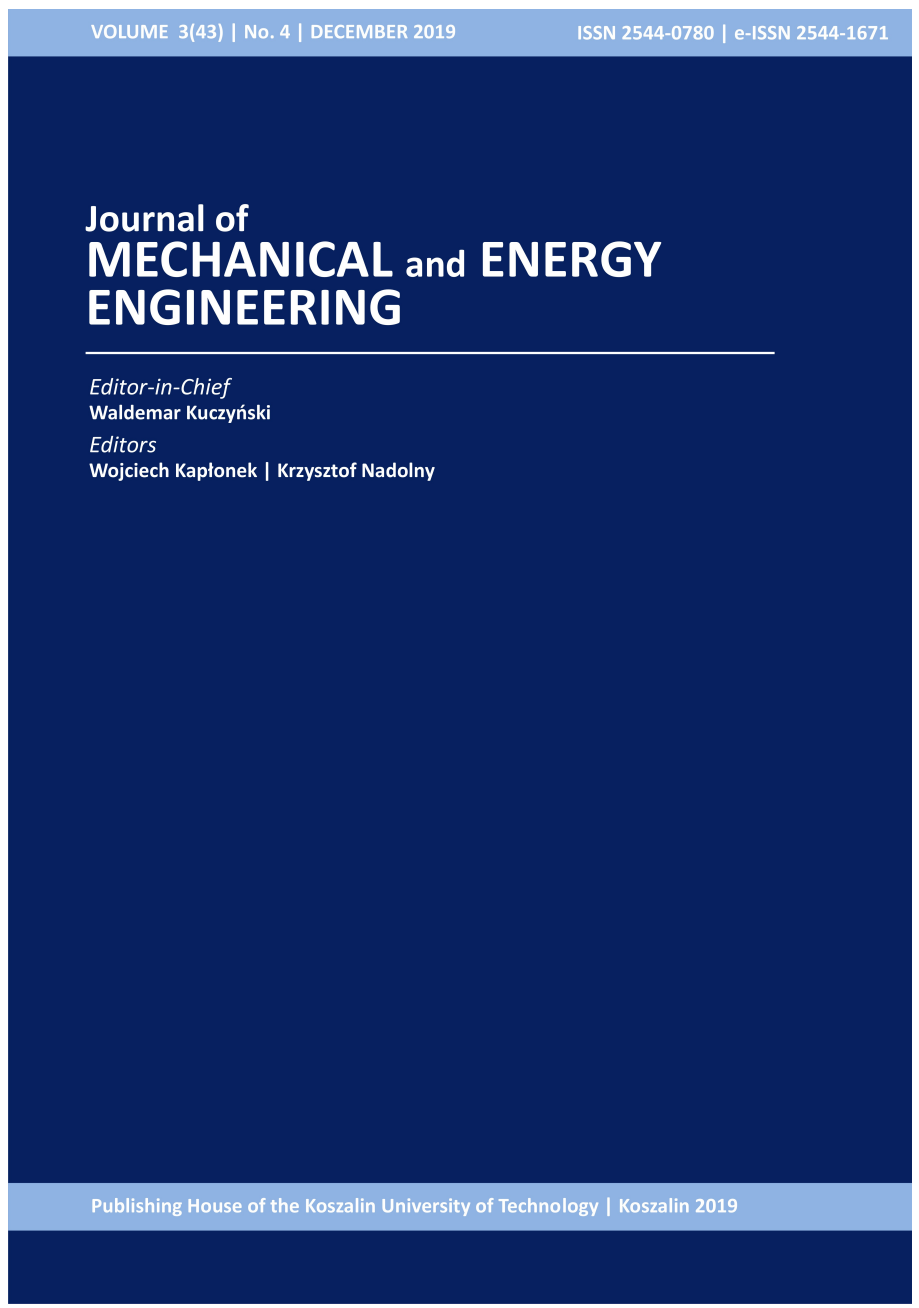

Journal of Mechanical and Energy Engineering

Website: jmee.tu.koszalin.pl

ISSN (Print): 2544-0780

ISSN (Online): 2544-1671

Volume: $3(43)$

Number: 4

Year: 2019

Pages: 317-322

Article Info:

Received 19 December 2019

Accepted 14 January 2020

\section{Open Access}

This article is distributed under the terms of the Creative Commons Attribution 4.0 (CC BY 4.0) International License (http://creativecommons.org/licenses/by/4.0/), which permits unrestricted use, distribution, and reproduction in any medium, provided you give appropriate credit to the original author(s) and the source, provide a link to the Creative Commons license, and indicate if changes were made. 


\title{
YEAR-ROUND OPERATION THE SOLAR POWERED HYBRID ADSORPTION-COMPRESSION REFRIGERATION CYCLE
}

\author{
Piotr CYKLIS ${ }^{1 *}$, Roman DUDA ${ }^{1}$ \\ ${ }^{1 *}$ Mechanical Department, Institute of Thermal and Process Engineering, Cracow University of Technology, \\ Cracow, Poland, e-mail: pcyklis@ mech.pk.edu.pl
}

(Received 19 December 2019, Accepted 14 January 2020)

\begin{abstract}
In our earlier papers a hybrid adsorption-compression refrigeration cycle was presented. The hybrid, two stages cycle is based only on the natural refrigerants: water and carbon dioxide. The main advantage of the hybrid cycle is that the carbon dioxide compression cycle is subcritical because during the year-round operation it is possible to maintain the condensing temperature below $20^{\circ} \mathrm{C}$. During the hot season, this is achieved by adsorption cooling, during cold seasons the wet cooling tower is sufficient. Already several years of experience, allowed to gather a considerable amount of measurement data. The refrigeration system is working in our laboratory constantly since 2013. In 2015 the adsorption system was upgraded by the manufacturer. In 2017 frequency inverter for wet tower fan controlling was introduced. The refrigeration chamber was used for tests with different content and operation of the refrigeration chamber (loading and unloading). The assumed $\mathrm{CO}_{2}$ evaporating temperature was $-35^{\circ} \mathrm{C}$. The averaged for HT (High Temperature) part of the cascade (adsorption cycle only) $\mathrm{COP}_{\mathrm{HT}}=0.51$ for the whole year 2018. This may be considered a very good performance. Averaged total COP for the cascade system: $\mathrm{COP}=0.9$ compared to $\mathrm{COP}=0.84$ for compression only refrigeration cascade, with much higher TEWI index. For comparison for two-stage compression (R407 $\mathrm{C}_{\mathrm{HT}}+\mathrm{R} 744_{\mathrm{LT}}$ ) cycle was used. This means that if the cooling tower fan operation is controlled using an inverter, adjusted to the actual heat removal demand, the hybrid cycle is not only ecological but also energetically efficient.
\end{abstract}

Keywords: hybrid compression adsorption refrigeration cycle

\section{INTRODUCTION}

The application of carbon dioxide as refrigerant is becoming increasingly popular due to the Montreal Protocol (1987) regulation. Carbon dioxide is introduced in compression systems, but due to the low critical temperature, the cycle requires very high pressure at the discharge side of the compressor and low efficiency is obtained. Therefore carbon dioxide cycles are used for low temperature (LT) stage at the two-stage refrigerating systems. On the other side sorption systems as $\mathrm{LiBr} / \mathrm{H}_{2} \mathrm{O}$ absorption or zeolite adsorption systems where water is the working fluid has low-temperature limit about $5-8^{\circ} \mathrm{C}$. This limits its application for refrigeration. Coupling two systems: sorption at the high-temperature stage and $\mathrm{CO}_{2}$ at the low-temperature stage, combines the possibility to use waste heat or solar heat as an energy source for the high-temperature stage, allowing the reduction of discharge pressure in the condenser of $\mathrm{CO}_{2}$ at the $\mathrm{LT}$ stage. In the HT (High Temperature) compression cycles another refrigerant, such as R410A, is frequently used. Several papers on $\mathrm{CO}_{2}$ applications in different refrigerating cycles has been shown in recent years [1]. Absorption systems are increasingly popular but mostly as one stage air cooling and heat pump systems using $\mathrm{LiBr}-\mathrm{H}_{2} \mathrm{O}[2,3,4]$. There is also interest in modelling and simulation of adsorption heat pumps, which allows the analysis of the winter cycle of the combined systems [5]. The adsorption technology is also frequently the subject of scientific investigation $[6,7,8,9,10,11]$. The range of produced absorption or adsorption units is from $8 \mathrm{~kW}$ up to $21 \mathrm{MW}$ cooling capacity. The choice of 
adsorption or absorption technology depends on load, price, and most of all temperature of the heat source for desorber heating [12]. The COP of the absorption cycle, with high-temperature generation (above $120^{\circ} \mathrm{C}$ ), using two-stage, double effect cycle, may be higher than for adsorption. For lower temperature sources such as solar cooling or central heating network, the application of absorption may not be possible at all. The different heat sources for cooling or refrigerating have been also analyzed in several published papers $[13,14,15,16]$. The adsorption technology makes it possible to apply $65^{\circ} \mathrm{C}$ heat source for desorber [17, 18]. This is the main difference between the possibilities of contemporary industrial adsorption and absorption technologies. There is also scientific interest in hybrid sorptioncompression cycles, however with other assumed aims and refrigerants than presented here [19, 20, 21, 22].

\section{EXPERIMENTAL METHODOLOGY}

In the Laboratory of Thermodynamics and Thermal Machines Measurements (Cracow University of Technology), the set-up with hybrid refrigerating compression/adsorption system was built in 2013
(Figs. 1,2,3,4,5) [23]. At the high temperature (HT) stage an adsorption system (ADS_L1) [24] coupled with tube type solar collectors (SOLAR_L4) and wet cooling tower (TOWER_L5) is applied. The lowtemperature stage (CO2_L2) is equipped with two parallel CO2 compressors.

One of the compressors is controlled by a variable frequency drive, both working in a cascade regime. A secondary fluid: ethylene glycol for solar collectors and transportation of heat, from low to hightemperature cycle is applied. The thermal fluxes between subsystems are presented in Fig. 1.

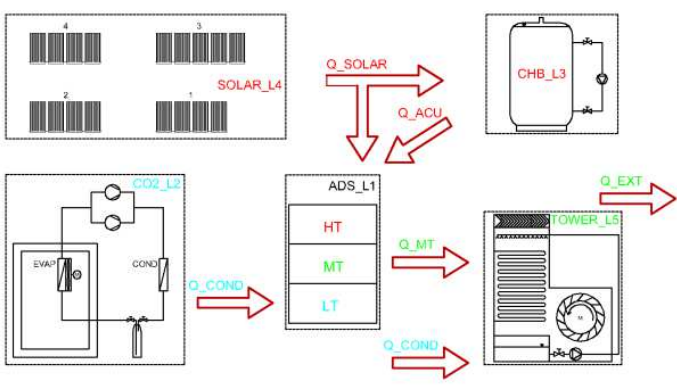

Fig. 1. Schematic diagram of a test setup

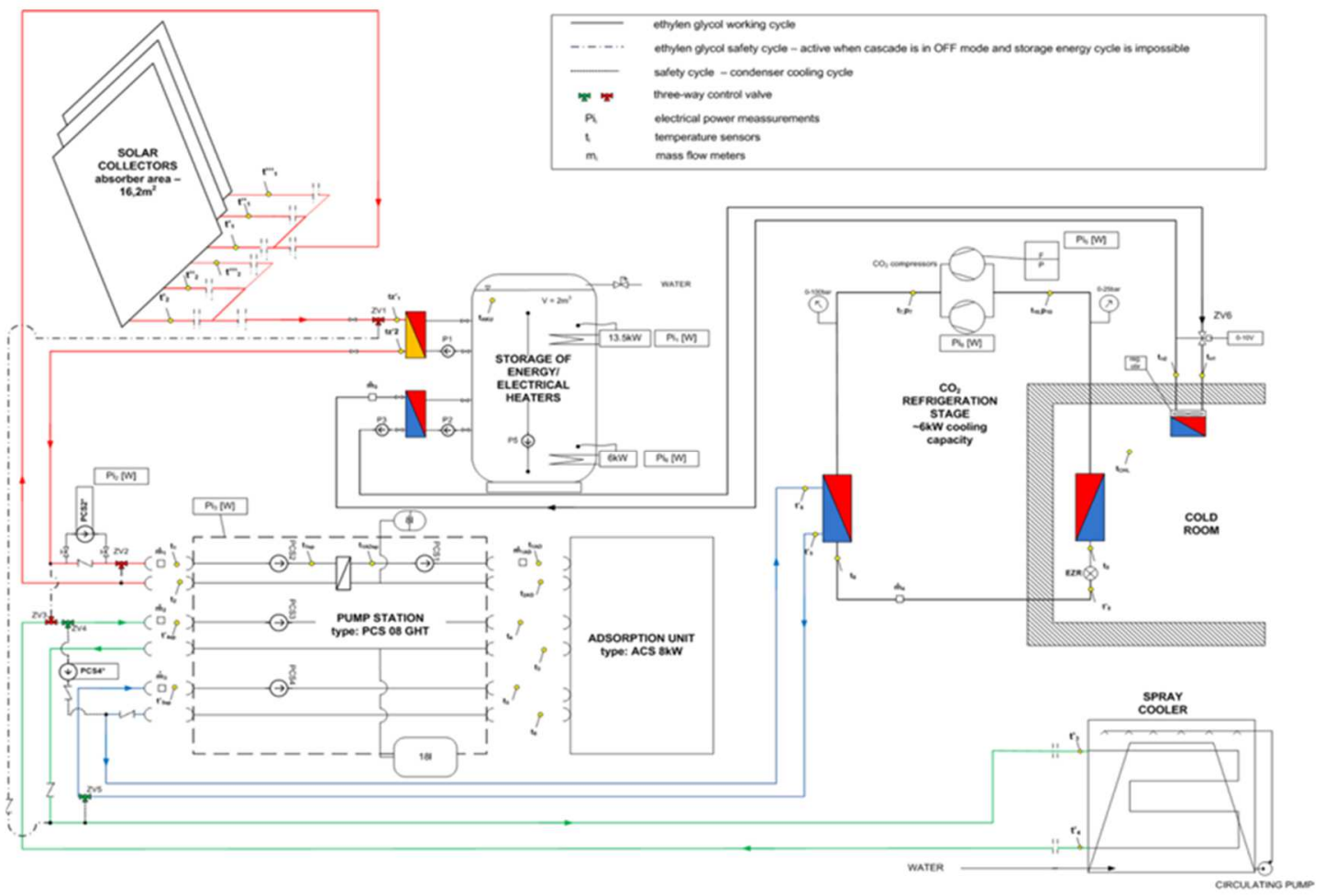

Fig. 2. Logical scheme of the hybrid system. SOLAR_L4 - solar collectors, ADS_L1- adsorption unit, CO2_L2 - LT compression stage, TOWER_L5 - wet cooling tower, CHB_L3 - heat accumulator, LT - low-temperature heat supply, MT - medium temperature heat for desorption system cooling, HT - high-temperature heat 
The main advantage of the hybrid cycle is that the carbon dioxide compression cycle is subcritical because during the whole year operation it is possible to maintain the condensing temperature below $20^{\circ} \mathrm{C}$. During the hot season, this is achieved by adsorption cooling, during cold seasons the wet cooling tower (Fig. 4) is sufficient.

This type of hybrid system requires a considerable amount of power for cooling tower fans. Therefore it is very important to control the fans of the wet cooling tower using frequency inverter. Already several years of experience, allowed to gather a considerable amount of measurement data. In this paper summarized results for heat transfer between system elements are shown. In Fig. 2 the logical schematic of the system is presented. Heat transfer between elements is denoted with subscribed arrows. The names of heat streams are denoted as subscripts in Figs 9, 11.

During our tests, all necessary temperatures and pressures were measured and then refrigerant and liquid enthalpy were calculated using NIST REFPROP. The mass flow rate or volumetric flow rate were also measured, as well as the power consumption of all devices including fans, compressors, pumps, and all control equipment. Ambient air parameters were also registered.

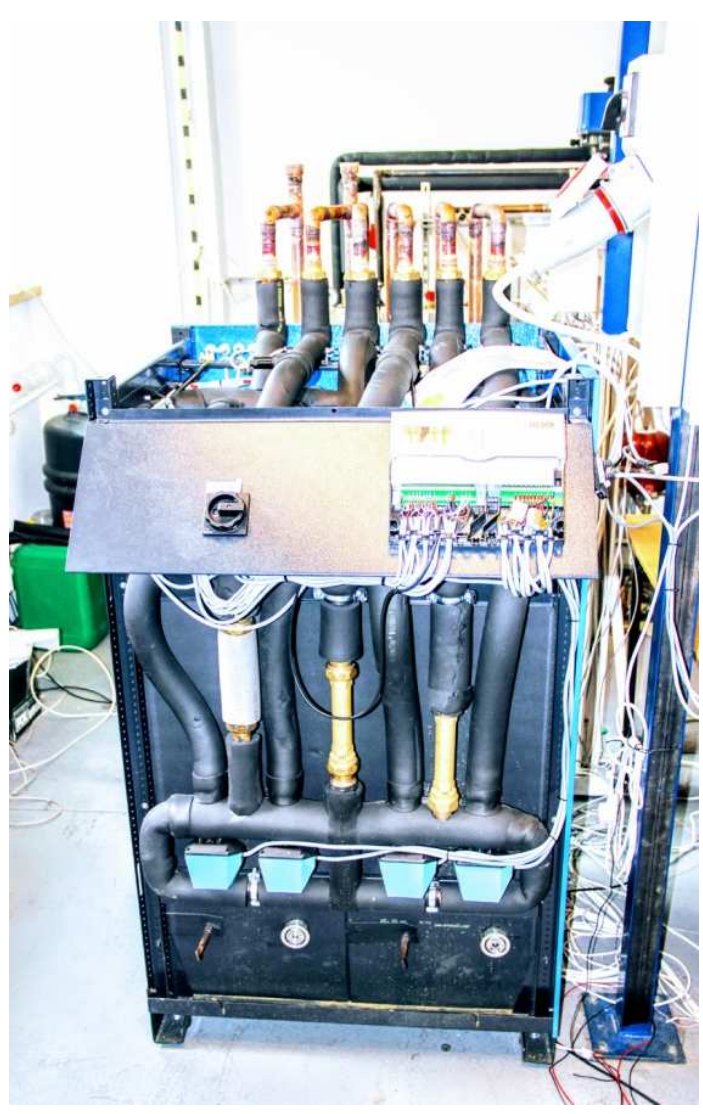

Fig. 3. Adsorption cycle main unit

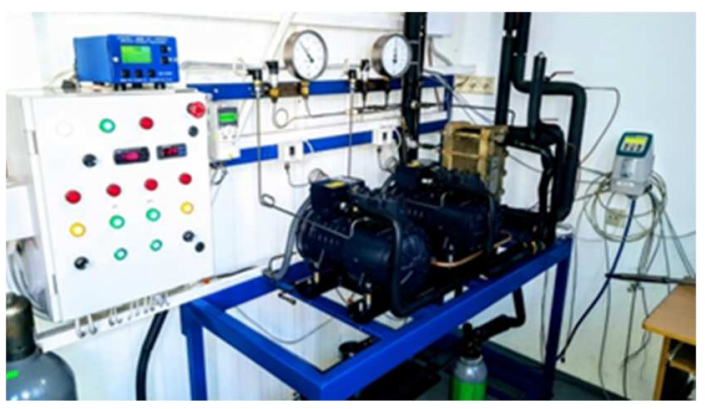

Fig. 4. Wet cooling tower

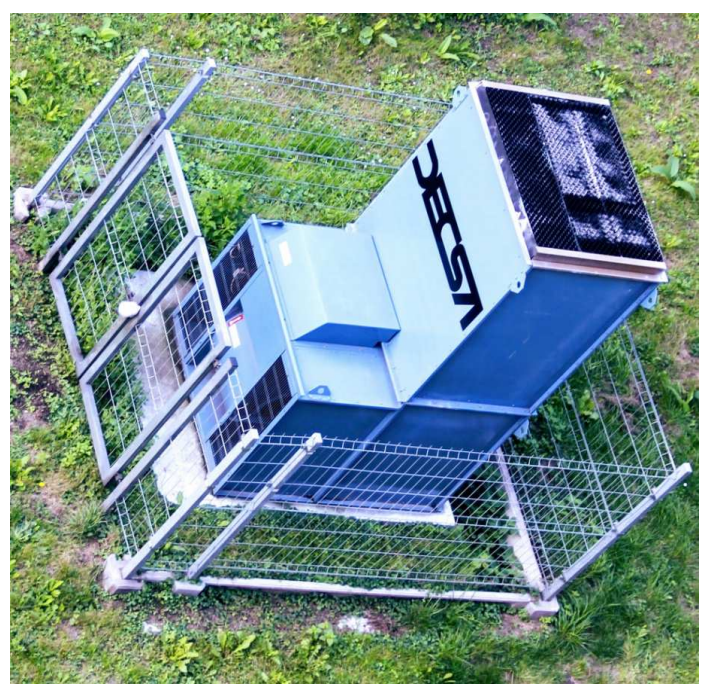

Fig. 5. $\mathrm{CO}_{2}$ compressors with controls

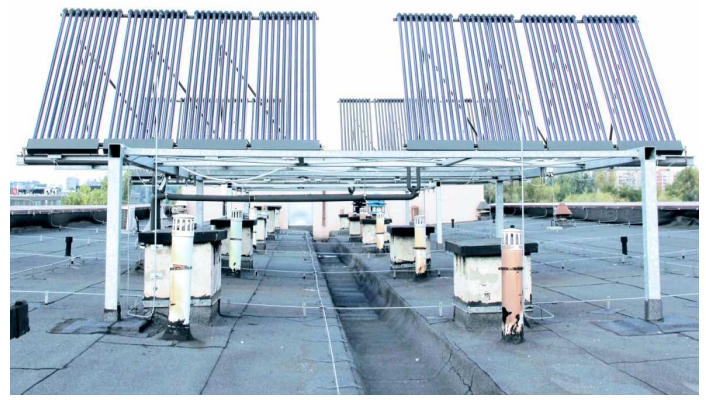

Fig. 6. Solar collectors

The refrigeration system (Fig. 1, 2, 3, 4, 5, 6) is operating in our laboratory constantly since 2013. In 2015 the adsorption system was upgraded by the manufacturer (SORTECH eCoo Fig. 3). Since 2017 fan in the cooling tower is controlled by the frequency inverter. The refrigeration chamber was used for tests with different content and operation (loading and unloading). The $\mathrm{CO}_{2}$ evaporating temperature was mostly $-35^{\circ} \mathrm{C}$. In Fig. 9 solar heat flux recovery by solar collectors for averaged day-in-month in 2018 is presented. 
Highest values of acquired solar heat flux are for May and August, lowest for December, September, and February in 2018. This, however, does not mean that solar heat gain, in case of the hybrid system, can be transformed directly into the cooling power of the adsorption system.

The COP of the adsorption system depends significantly on the temperature and humidity of the ambient air and the amount of heat removed by the cooling tower. It is presented in Figs 9, 11.

In Fig. 10 an example characteristics of a wet cooling tower is presented. These functions were averaged from the results of the experimental tests. Usually, this power is neglected in the literature, while analyzing cycle COP. However, in the real working conditions total COP of a system shall include as energy loss also a power supply for cooling fans and pumps. Therefore frequency inverters for the tower fan and pump were introduced and function shown in Fig. 10 were used for system control.

The measurement system used in the facility is described in table 1 .

Tab. 1. Measuring equipment installed in the refrigeration adsorption-compression hybrid system

\begin{tabular}{|c|c|c|}
\hline Sensor & Class & Usefull range \\
\hline $\begin{array}{l}\text { Introl IT-CF-1 } \\
\text { Pt100 }\end{array}$ & B & $\begin{array}{l}-25 \sim 200 ;-50 \sim 150 \\
0 \sim 150^{\circ} \mathrm{C}\end{array}$ \\
\hline Introl & $0.03 \%$ & $4 \sim 20 \mathrm{~mA}$ \\
\hline $\begin{array}{c}\text { SIEMENS } \\
\text { MASSFLO } 2100\end{array}$ & $0.01 \%$ & $0 \sim 1000 \mathrm{~kg} / \mathrm{h}$ \\
\hline $\begin{array}{c}\text { SIEMENS MASS } \\
6000\end{array}$ & $0.01 \%$ & $0.0002 \sim 0.2786 \mathrm{~kg} / \mathrm{s}$ \\
\hline $\begin{array}{c}\text { Hoffer Flow } \\
\text { Controls ACEII }\end{array}$ & $0.05 \%$ & $10 \sim 110 \mathrm{l} / \mathrm{min}$ \\
\hline $\begin{array}{l}\text { Hoffer Flow } \\
\text { Controls }\end{array}$ & $0.05 \%$ & $\begin{array}{l}4.73 \sim 35.96 ; \\
6.62 \sim 60.57 ; \\
9.46 \sim 109.781 / \mathrm{min}\end{array}$ \\
\hline $\begin{array}{c}\text { KEP } \\
\text { BATRTM2AC }\end{array}$ & $0.05 \%$ & $\begin{array}{l}0 \sim 36 ; 0 \sim 60 ; 0 \sim 110 \\
1 / \mathrm{min}\end{array}$ \\
\hline Vegabar 17 & $0.05 \%$ & $0 \sim 100$ bar \\
\hline Vegabar 17 & $0.05 \%$ & $0 \sim 25$ bar \\
\hline LUMEL & $0.01 \%$ & $\begin{array}{l}0 \sim 200 ; 0 \sim 700 ; \\
0 \sim 3000 ; 0 \sim 8000 ; \\
0 \sim 10000 ; 0 \sim 15000 \\
\text { W }\end{array}$ \\
\hline
\end{tabular}

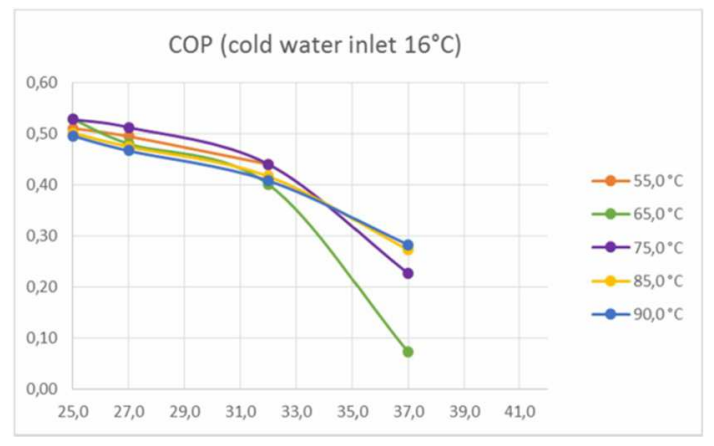

Fig. 7. The adsorption cycle COP for $16^{\circ} \mathrm{C}$ water inlet

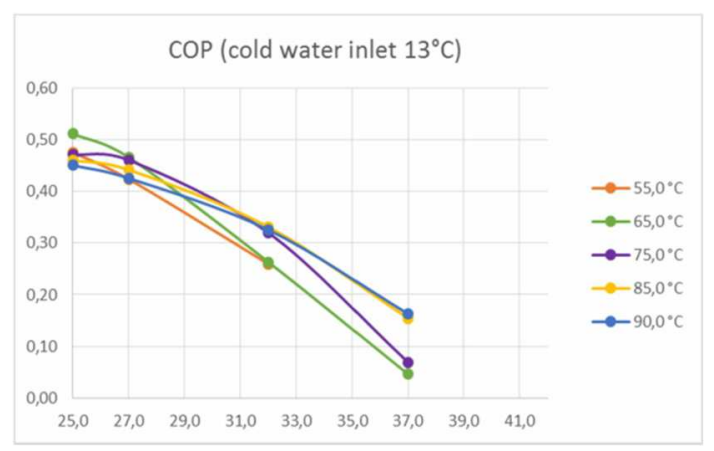

Fig. 8. The adsorption cycle COP for $13^{\circ} \mathrm{C}$ water inlet

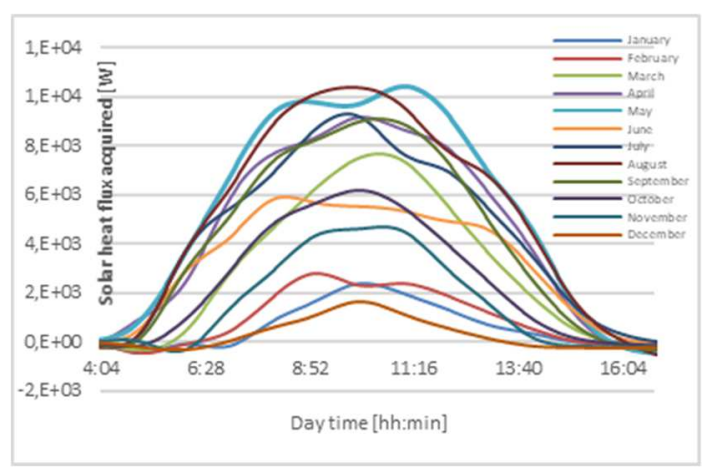

Fig. 9. Solar heat recovery in 2018 for an averaged day in a month

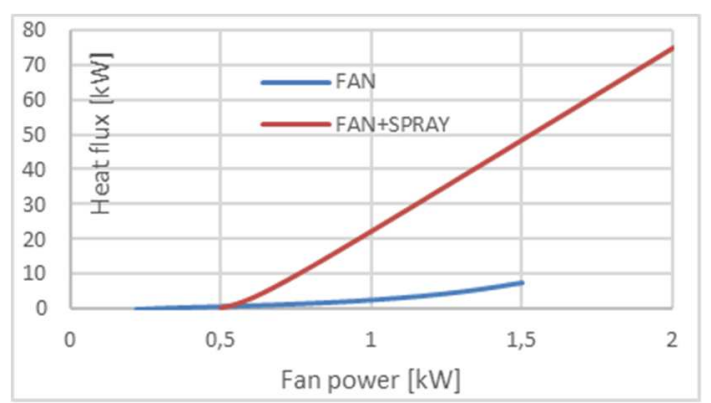

Fig. 10. Heat flux in the cooling tower related to the fan revolution speed/power 


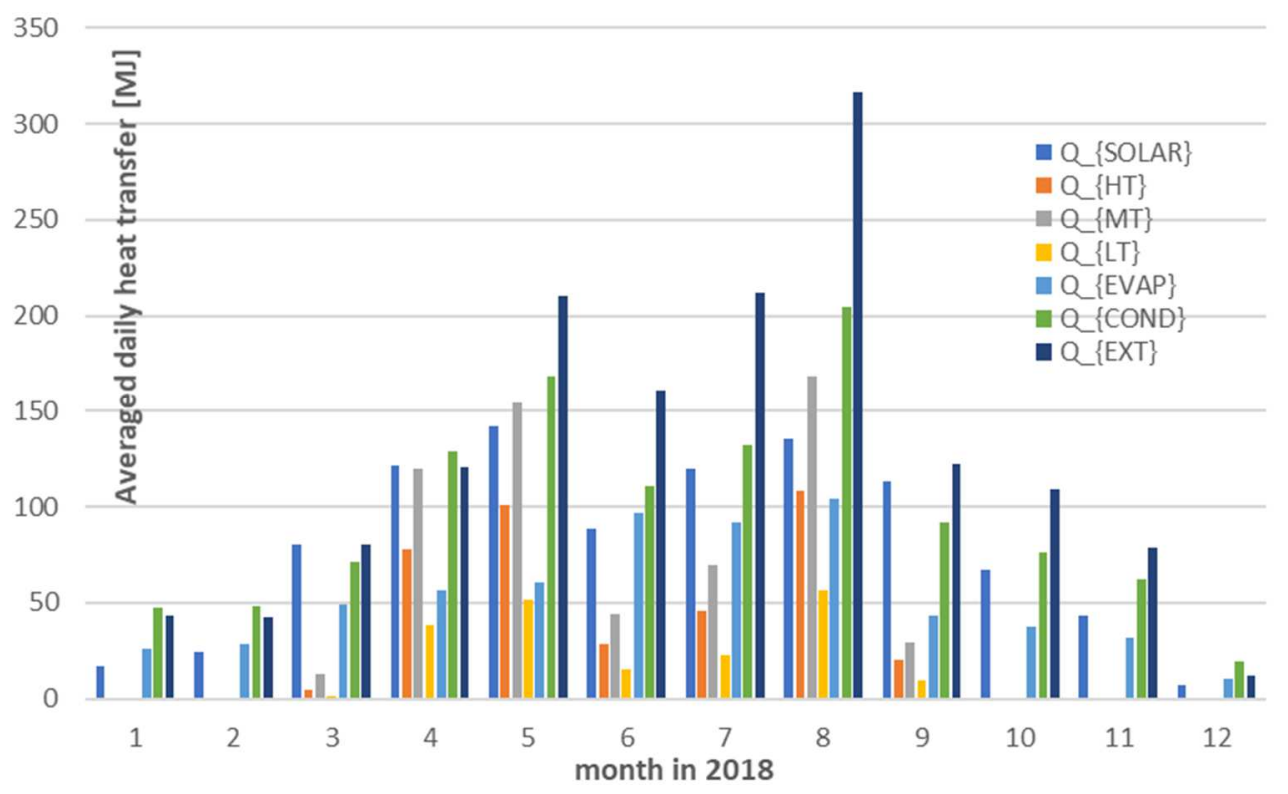

Fig. 11. Daily heat transfer in the heat exchangers

\section{PERFORMANCE RESULTS}

In Fig. 11 heat transfer energy between subsystems denoted in Fig. 2 during the average day (24 hours) in 12 months is presented. Useable heat transfer QLT values shown in Fig. 11 are lower in hot days than expected because of higher MT ambient temperature, which is a significant factor for adsorption cycle COP (Figs. 7.8). The adsorption system was not used for $\mathrm{CO}_{2}$ condenser cooling in the period of 1.01-31.03.2018 and 1.10.2018-31.12.2018. During this time the cooling tower was sufficient for the direct $\mathrm{CO}_{2}$ condenser cooling. The thermodynamic efficiency of the system may be estimated using the COP (Coefficient of Performance). Thermodynamic analysis always denotes efficiency as the achieved energy result divided by the energy cost. This seems obvious but in case of hybrid systems powered partially by renewables, this definition does not reflect the real thermodynamical efficiency. The COP for adsorption system used for cooling is defined traditionally as:

$$
\operatorname{COP}_{H T}=\frac{Q_{\text {cond }}}{Q_{H T}},
$$

where: $Q_{\text {cond }}$ - heat energy removed from the lowtemperature source (in this case evaporator $\mathrm{CO}_{2}, Q_{H T}-$ heat for adsorption generator

The COP for all year according to formula (1) is 0.51 . This number is consistent with the producer's data [24], higher than expected for long-time operation.

For the compression, refrigeration cycle COP is defined as:

$$
C O P=\frac{\dot{Q}_{\text {evap }}}{N_{\text {compr }}},
$$

where: $Q_{\text {evap }}-\mathrm{CO}_{2}$ evaporation heat, $N_{\text {compr }}-$ compressors power.
In the case of two stages, compression-only cycle equation (2) is also valid.

Total $\mathrm{COP}=0.9$ for this system was calculated using whole year values of heat and power. For similar conditions, the compression-only cascade $\mathrm{COP}=0.84$. Those results, however, neglect in both cases power supply for auxiliary systems (pumps, fans and control devices), which in the case of a hybrid cascade is higher. For the compression cascade, TEWI index is $60 \%$ higher than hybrid cascade [23].

\section{CONCLUSIONS}

The averaged for HT part of the cascade (adsorption cycle only) $\mathrm{COP}_{\mathrm{HT}}=0.51$ for the whole year 2018. This may be considered very good performance for adsorption system powered by waste/renewable heat. This means that about half of the total solar energy acquired by solar collectors was used. Calculated from yearly averaged energy transfers total COP for the cascade system was $\mathrm{COP}=0.9$. For double stage compression-only refrigeration cascade for similar conditions calculated $\mathrm{COP}=0.84$. For comparison for two-stage compression

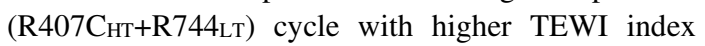
was used.

The cooling tower fan operation is controlled using inverter adjusted to the actual heat removal demand. This allows for significant electric power requirement reduction for the system.

During the cold season, the adsorption cycle may work as a heat pump because $\mathrm{CO}_{2}$ condenser was cooled directly by the cooling tower. This means also that the solar system is not utilized as an energy source for the $\mathrm{CO}_{2}$ compression system and become a heat source for the heat pump. In this case, three heat 
sources for a heat pump is used: solar collectors, condenser and compressor cooling, ambient air as a low-temperature heat source for a heat pump. This solution increases total Renewable Energy Source (RES) usage for the whole year.

\section{References}

1. I. Suamir and S. Tassou, "Performance evaluation of integrated trigeneration and $\mathrm{CO} 2$ refrigeration systems," Applied Thermal Engineering, no. 50, pp. 1487-1495, 2013.

2. D. Kim and C. Infante Ferreira, "Solar refrigeration options - a state-of-the-art review," International Journal of Refrigeration, no. 31, pp. 3-15, 2008.

3. G. Florides, "Design and construction of a $\mathrm{LiBr}-$ water absorption machine," Energy Conversion and Management, no. 44, pp. 2483-2508, 2003.

4. P. Cyklis and G. Brak, "LiBr-H2O absorption cycle design for whole year use in medium climate conditions," Transactions of the Institute of Fluid-Flow Machinery, vol. 121, pp. 49-66, 2008.

5. G. Starace, F. Carluccio and C. Bongs, "Modeling and Simulation of a Gas Absorption Heat Pump," Washington DC, 2014.

6. A. Grzebielec, "Experimental study on adsorption heat pump," Archives of thermodynamics, vol. 30, pp. 189200, 2009.

7. Z. Tamainot-Telto and R. Critoph, "Adsorption refrigerator using monolithic carbon-ammonia pair," International Journal of Refrigeration, no. 20, p. 146$155,1997$.

8. K. Srinivasan, "Performance evaluation of combined adsorption refrigeration cycles," International Journal of Refrigeration, no. 34, pp. 129-137, 2011.

9. C. Chen, R. Wang, Z. Xia, J. Kiplagat and Z. Lu, "Study on a compact silica gel-water adsorption chiller without vacuum valves: Design and experimental study," Applied Energy, no. 87, p. 2673-2681, 2010.

10. D. Wang, Z. Xiaa, J. Wua, R. Wang, H. Zhai and W. Dou, "Study of a novel silica gel-water adsorption chiller. Part I. Design and performance prediction,' International Journal of Refrigeration, no. 28, p. 10731083, 2005.

11. G. Zhang, D. Wang, J. Zhang, Y. Han and S. Wanchao, "Simulation of operating characteristics of the silica gelwater adsorption chiller powered by solar energy," Solar Energy, no. 85, p. 1469-1478, 2011.

12. K. Ullah, R. Saidur, H. Ping, R. Akikur and N. Shuvo, "A review of solar thermal refrigeration and cooling methods," Renewable and Sustainable Energy Reviews, no. 24 , p. 499-513, 2013.

13. B. Saha, S. Koyama, J. Lee, K. Kuwahara, K. Alam, Y. Hamamoto, A. Akisawa and T. Kashiwagi, "Performance evaluation of a low-temperature waste heat driven multi-bed adsorption chiller," International Journal of Multiphase Flow, no. 29, pp. 1249-1263, 2003.

14. M. Izquierdo, A. Syed, P. Rodriguez, G. Maidment, J. Missenden, A. Lecuona and R. Tozer, "A novel experimental investigation of a solar cooling system in Madrid," International Journal of Refrigeration, no. 28 , p. 859-871, 2005 .

15. K. Joudi and N. Dhaidan, "Application of solar assisted heating and desiccant cooling systems for a domestic building.," Energy Conversion Managment, no. 42, pp. 995-1022, 2001.

16. R. Wang, M. Li, Y. Xu and J. Wu, "An energy efficient hybrid system of solar powered water heater and adsorption ice maker," Solar Energy, no. 68, p. 189-195, 2000.
17. B. Saha, L. El-Sharkawya, A. Chakrabortya, S. Koyama, N. Banker, P. Duttab, M. Prasad and K. Srinivasana, "Evaluation of minimum desorption temperatures of thermal compressors in adsorption refrigeration cycles," International Journal of Refrigeration, no. 29, pp. 11751181, 2006.

18. B. Saha, S. Koyama, T. Kashiwagi, A. Akisawa, K. Ng and H. Chua, "Waste heat driven dual-mode, multi-stage, multi-bed regenerative adsorption system," International Journal of Refrigeration, no. 26, p. 749-757, 2003.

19. H. Wei, S. Liuli, D. Zheng, J. Hongguang, M. Sijun and J. Xuye, "New hybrid absorption-compression refrigeration system based on cascade use of midtemperature waste heat," Applied Energy, no. 106, p. 383-390, 2013.

20. S. Garimella, A. Brown and A. K. Nagavarapu, "Waste heat driven absorption/vapor-compression cascade refrigeration system for megawatt scale, high-flux, lowtemperature cooling," International Journal of Refrigeration, no. 34, pp. 1776-1785, 2011.

21. Z. Danxing and M. Xuelin, "Ultimate refrigerating conditions, behavior turning and a thermodynamic analysis for absorption-compression hybrid refrigeration cycle," Energy Conversion and Management, no. 56, p. 166-174, 2012.

22. N. Banker, P. Dutta, M. Prasad and K. Srinivasan, "Performance studies on mechanical adsorption hybrid compression refrigeration cycles with HFC 134a," International Journal of Refrigeration, no. 31, p. 13981406, 2008

23. P. Cyklis, "Two stage ecological hybrid sorptioncompression refrigeration cycle," International Journal of Refrigeration, vol. 48, pp. 121-131, 2014.

24. SorTech, "SorTech Adsorption Chiller ACS 08/ACS 15, Design manual, Version 2.2," SorTech, Halle, 2009

\section{Biographical notes}

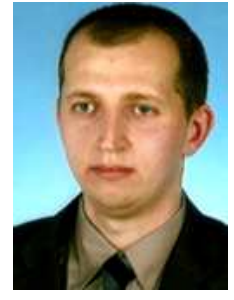

Roman Duda received his MSc in Power Engineering (specialisation: power engineering systems and facilities) in 2012 from Institute of Thermal Power Engineering at the Faculty of Mechanical Engineering of Cracow University of Technology, after the work in iBros technic, has been a Researcher for the Institute of Thermal and Process Engineering at the Cracow University of Technology, where currently he works as assistant. His scientific interest is focused on issues related to the utilisation of renewable energy for cold production.

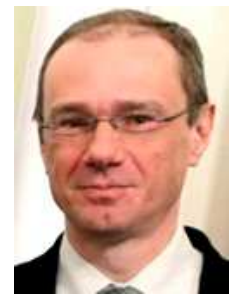

Piotr Cyklis received his MSc in Mechanical Engineering in 1984 at the Faculty of Mechanical Engineering of the Cracow University of Technology, and Professor title in 2010. Since 1984 has been a researcher at the CUT, Laboratory of Thermodynamics and Thermal Machines Measurements. Specialising in innovative anticlockwise cycles, thermal processes and volumetric compressors. 